\title{
Pengaruh Fraksi Ejakulasi terhadap Motilitas Spermatozoa Kambing Peranakan Etawa (Capra aegagrus)
}

\author{
The Effect of Ejaculation Fraction on the Spermatozoa Motility of \\ Etawa Crossbred Goat (Capra aegagrus)
}

\author{
Ayu Naila Nahdiyah ${ }^{1 *}$, Hari Santoso $^{2 * *}$, Hasan Zayadi ${ }^{3}$ \\ ${ }^{1}$ Jurusan Biologi Fakultas Matematika dan Ilmu Pengetahuan Alam, Indonesia
}

\begin{abstract}
ABSTRAK
Fraksi Ejakulasi pada Kambing Peranakan Etawa (PE) mempunyai kualitas spermatozoa dengan berbagai standart, salah satunya motilitas spermatozoa. Motilitas Spermatozoa menjadi hal yang sangat penting untuk diperhatikan dalam pengembangan teknik Inseminasi Buatan, karena keberhasilan dalam teknik Inseminasi Buatan sangat dipengaruhi oleh motilitas yang dimiliki spermatozoa. Motilitas spermatozoa semen diketahui melalui proses pemeriksaan daya gerak spermatozoa dalam uji mikroskopis. Penelitian ini bertujuan untuk mengetahui pengaruh fraksi ejakulasi terhadap motilitas spermatozoa kambing PE. Menggunakan metode percobaan dengan rancangan acak kelompok (RAK) terdiri atas 2 kelompok perlakuan yakni Kelompok $1\left(\mathrm{~K}_{1}\right)$ adalah fraksi 1dan kelompok $2\left(\mathrm{~K}_{2}\right)$ adalah fraksi 2, ulangan masing-masing perlakuan 8 ulangan dan unit penelitian berjumlah 16. Penampungan semen dilakukan satu kali seminggu dengan teknik AV (Artificial Vagina). Penampungan dilakukan sampai ejakulat kedua. Segera setelah penampungan dilakukan pengukuran uji motilitas spermatozoa menggunakan sperm vision analyser IVOS II. Hasil uji pengamatan fraksi ejakulasi menggunakan t-test independent sample menunjukkan nilai $\mathrm{t}_{\text {hit }}=0,700$ dan $\mathrm{t}_{(0,025)}=2,14$ maka $\mathrm{t}_{\text {hit }}<\mathrm{t}_{(0,025)}$ artinya $\mathrm{H}_{0}$ di terima, yang mempunyai arti motilitas spermatozoa kambing PE dari fraksi 1 dan fraksi 2 tidak berbeda nyata.
\end{abstract}

Kata kunci: fraksi ejakulasi, motilitas spermatozoa, kambing PE

\begin{abstract}
The ejaculation fraction on Etawa crossbred goat (PE goat) has various standard spermatozoa qualitues, one of which ismotility of spermatozoa. The motility of spermatozoa is very important to note in the development of artificial insemination techniques, because the success in artificial insemination techniques is strongly influenced by the motility of spermatozoa. The motility of semen spermatozoa is known through the process of examining the movement of spermatozoa in microscopic testing. The aim of this research was find out the effect of ejaculation fraction on motility of PE goat spermatozoa. Using an experimental method with a group's random consisting of two treatment groups; $K 1$ is fraction land $K 2$ is a fraction 2. The Replication of each treatment was eight replications and a total of sample research was 16 unit. The semen was collected once a week using artificial vagina (VA) technique. The semen collecting until the second ejaculation and motility test of spermatozoa were immediately measured use sperm vision analyzers IVOS II. The test results of the ejaculation fraction observation using an independent sample $t$-test showed the value of $t_{\text {hit }}=0.700$ and $t(0.025)$ than $2.14 t$ hit $<t$ (0.025) meaning that $H_{0}$ was received, there was no significant ejaculation fraction 1 with ejaculatory fraction 2; motility meaning of the spermatozoa from the PE goat of a fraction 1 and faction 2 not different significantly.
\end{abstract}

Keywords: ejaculation fraction, motility of Spermatozoa, PE goat.

\footnotetext{
*) Ayu Naila Nahdiyah, Jurusan Biologi FMIPA UNISMA, Jl. Mondoroko 1 no 60 Singosari, Malang 65153 Telp./handphone.081234026238/089612795543 e-mail: ay.nailanahdiyah@gmail.com

$\left.{ }^{* *}\right)$ Drs. H. Hari Santoso, M.Biomed, Jurusan Biologi FMIPA UNISMA, Jl. MT Haryono 65144 Telp 082331449560

E-mail: harisantoso.m.biomed@gmail.com
}

Diterima Tanggal 29 Juli 2019 - Dipublikasikan Tanggal 25 Januari 2020 


\section{Pendahuluan}

Indonesia sebagai negara agraris, sebagian besar masyarakatnya hidup sebagai petani dan peternak. Sasaran pembangunan sektor peternakan yang akan di capai adalah peningkatan produksi peternakan, melalui perbaikan mutu hewan ternak berkualitas agar dapat menjaga efisiensi produksi ternak serta menjaga usaha peternakan terus meningkat [1]. Kambing Etawa berasal dari wilayah Jamnapari (India), dengan tipe dwiguna yakni sebagai penghasil susu dan daging [2]. Melalui SK Kementan Nomor 695/Kpts/PD.410/2/2013, menetapkan rumpun kambing PE secara formal dapat dibudidayakan dan dikembangkan sebagai hewan ternak melalui teknik insiminasi buatan (IB). IB merupakan salah satu upaya peningkatan populasi ternak kambing maupun sapi, guna perbaiakan mutu dan hasil budidaya peternakan secara efektif dan efisien [3].

Inseminasi buatan merupakan teknik perkawinan dengan memasukkan semen segar atau semen beku ke dalam saluran kelamin kambing atau sapi betina dengan menggunakan alat yang dibuat oleh manusia. Tujuannya untuk perbaikan mutu genetika ternak, menghindari penyebaran penyakit kelamin, meningkatkan jumlah keturunan dari pejantan unggul, mengoktimalkan penggunaan semen untuk mengawini lebih banyak hewan betina [4].

Produksi semen dengan motilitas yang baik sangat menentukan keberhasilan perkawinan seekor pejantan. Motilitas semen yang rendah akan menurunkan pencapaian angka kebuntingan. Motilitas dari semen diketahui dengan proses pemeriksaan secara mikroskopis, yakni pemeriksaan daya gerakannya. Pemeriksaaan motilitas ini diperlukan untuk menentukan nilai motilitas semen dan daya reproduksi pejantan [5]. Feredis [6] Motilitas digunakan sebagai patokan paling sederhana dalam penilaian kualitas semen. Persentase spermatozoa motil (bergerak progresif) dapat digunakan sebagai ukuran kesanggupan untuk membuahi ovum [7] serta ejakulasi yang terlampau sering dan kontinyu akan menurunkan motilitas semen yang dihasilkan [8].

Ejakulasi yang tinggi akan menginduksi perubahan spersifik pada spermatozoa khususnya perubahan konstitusi biokimia spermatozoa, sehingga akan mempengaruhi kemampuan fertilisasi spermatozoa saat dideposisikan ke dalam saluran reproduksi betina, baik dengan menggunakan teknologi inseminasi buatan (IB) atau perkawinan alam [9].

Berdasarkan uraian diatas maka dilakukan penelitian dengan tujuan mengetahui pengaruh fraksi ejakulasi terhadap motilitas spermatozoa kambing PE (Peranakan Etawa) yang diharapkan akan dapat menentukan kriteria dalam pemilihan calon pejantan sebagai pedoman budidaya kambing.

\section{Material dan Metode}

\section{Bahan dan Alat}

Bahan yang digunakan dalam penelitian ini adalah semen segar kambing peranakan Etawa (PE) hasil penampungan Balai Besar Inseminasi Buatan (BBIB) Singosari, Lubricating jelly, $\mathrm{NaCl}$ 0,9\% dan air bersih mengalir, sabun/tepol $2 \%$.

Alat yang digunakan dalm penelitian ini sebagai berikut: kompor, baskom, sikat, oven/ sterilisator, lemari/wadah steril, almunium foil, pinset, sterilisasi UV (Ultra Violet), Artificial Vagina (AV), karet cone, tag kode pejantan, karet, selongsong, kain hitam, alat pompa, galss stick, collection tube, erlemeyer, tabung reaksi, vortex mixer, gelas, mikropipet, Sperm Vision Analyser IVOS II, object glass, dan cover glass.

\section{Metode}

Ditinjau dari segi prosedur dan pola yang ditempuh oleh peneliti dalam penelitian ini, termasuk jenis penelitian deskriptif kuantitatif. Pengambilan sampel menggunakan random sampling dengan rancangan acak kelompok (RAK) dengan 2 perlakuan dan 8 kali ulangan, sehingga unit penelitian berjumlah 16 sampel. Kambing PE yang ditampung semennya dua kali dalam satu waktu penampungan. 


\section{Cara Kerja}

Cara Kerja penelitian sebagaimana dijelaskan berikut: peralatan yang digunakan di sterilisasi terlebih dahulu dan di siapkan vagina buatan / AV (Artificial Vagina) untuk penampungan semen kambing PE. Selanjutnya dilakukan proses penampungan semen kambing PE di area penampungan yang telah tersedia untuk kemudian di periksa motilitas dari spermatozoa semen hasil penampungan tersebut menggunakan unit intrumen Sperm Vision Analyser IVOS II, selanjutnya data yang telah terkumpul di analisis menggunakan uji t tidak berpasangan/ uji t-test independent sample menggunakan program t-test independent sample (SPSS 16.0 for windows) under Windows system computer.

\section{Hasil dan Diskusi}

Diagram hasil pengamatan ejakulasi dan motilitas spermatozoa semen segar pada pejantan Kambing PE seperti pada Gambar 1.

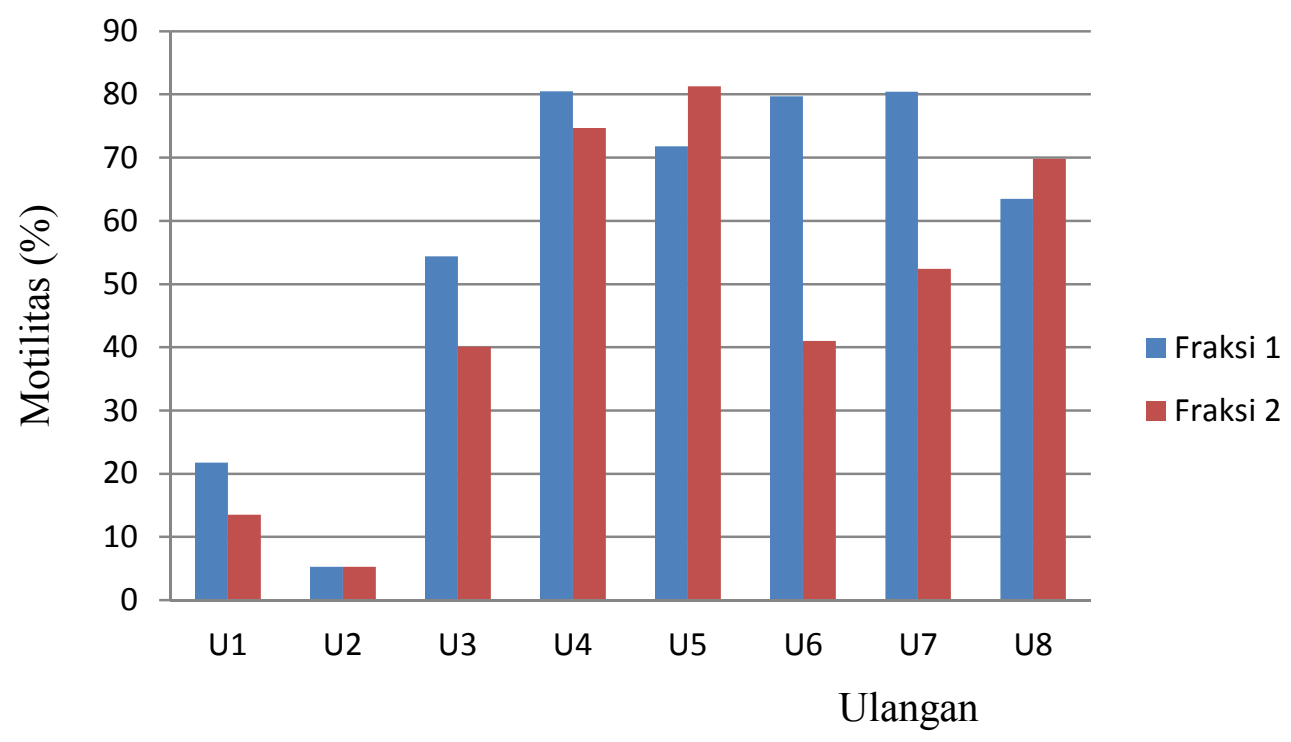

Gambar 1. Diagram motilitas spermatozoa kambing PE

Berdasarkan hasil pengamatan dalam diagram tersebut menunjukkan bahwa pada fraksi pertama nilai motilitas terbesar adalah pada nilai $80,50 \%$ dan motilitas terendah pada nilai $5,30 \%$. Sedangkan motilitas spermatozoa semen kambing PE fraksi kedua nilai motilitas terbesar pada nilai $81,30 \%$ dan nilai terendahnya pada 5,30\%. Jika dilihat dari nilai yang diperoleh dari hasil pemerikasaan motilitas spermatozoa semen segar kambing PE fraksi pertama dan kedua nilai motilitas terbesar pada fraksi kedua yakni sebesar $81,30 \%$ dannilai motilitas terendah dimiliki oleh fraksi pertama yakni sebesar 5,30\%. Serta jika dilihat dari hasil diagram motilitas spermatozoa kambing PE pada fraksi pertama memilikirata-rata diagram hasil nilai motilitas yang lebih besar dibandingkanfraksi ke 2 .

Adanya perbedaan yang signifikan pada masing-masing data hasil uji motilitas sample semen karena sample semen yang digunakan dari beberapa individu kambing PE yang berbeda diduga karena adanya beberapa faktor yang mempengaruhi motilitas yang dimiliki speramtozoa diantranya yaitu: faktor usia individu, berat badan individu, lingkar skrotum, lingkungan (suhu dan cahaya) keadaan individu seperti kesehatan/ stress, lingkungan, suhu AV (Artificial Vagina) yang digunakan 
saaat penampungan, kecocokan individu yang akan di ambil semennya dengan kambing pemancing, keterampilan petugas penampungan dan pendeknya jarak jadwal penampungan tiap individu.

Susilawati dkk. [10] menyatakan bahwa semen yang berkualitas dari seekor pejantan unggul dapat dipengaruhi oleh beberapa faktor, antara lain umur pejantan, sifat genetika, suhu, lingkungan, frekuensi ejakulasi dan nutrisi makanan. Motilitas semen kambing juga dipengaruhi dipengaruhi oleh ukuran badan, dan berbagai faktor lain [11]. Umur ternak juga merupakan salah satu faktor yang mempengaruhi kualitas semen segar [12].

Berdasarkan data yang diperoleh hasil uji T-Test Independent tidak berpasangan menunjukkan nilai signifikansi $=0,496$, yang apabila hasil nilai signifikansi $\geq$ dari 0,025 menunjukkan tidak ada perbedaan yang signifikan antara perlakuan, dengan nilai $t$ hit $=0,700$ dan $t(0,025)=2,14$ sehingga $t$ hitung $<$ t 0,025 artinya tidak berbeda nyata. Dengan demikian karena hasil uji T-Test Independent/ tidak berpasangan dari kedua hasil motilitas masing- masing fraksi menunjukkan $t$ hitung $<\mathrm{t} 0,025$ maka tidak ada perbedaaan diantara kedua jenis ejakulasi terhadap motilitas spermatozoa.

Fraksi ejakulasi tidak berbeda nyata terhadap motilitas spermatozoa artinya tidak ada interaksi antara fraksi ejakulasi dengan motilitas spermatozoa. Tidak adanya perbedaan yang signifikan karena kambing yang diukur merupakan satu rumpun yaitu kambing peranakan Etawa (PE), sehingga kualitas genetik yang mempengaruhi nilai motilitas tidak berbeda nyata atau tidak ada pengaruh. Hal ini sesuai dengan penelitian Mostari dkk. [13] bahwa persentase motilitas individu spermatozoa pada bangsa kambing yang berbeda menunjukkan perbedaaan yang signifikan. Sehingga apabila rumpun kambing yang sama diukur nilai motilitasnya, perbedaaan nilai motilitas tidak akan jauh berbeda nyata ataupun tidak ada pengaruh. Selain itu lingkungan juga mempengaruhi nilai motilitas. Semen yang ditampung disuhu lingkungan yang sama mempengaruhi nilai motilitas yang tidak berbeda nyata.

Tidak adanya perbedaan dari hasil evaluasi ini kemungkinan karena perlakuan memiliki perngaruh yang sangat kecil pada saat proses spermatogenesis, sehingga interval koleksi tidak memiliki pengaruh terhadap motilitas spermatozoa. Hal ini sesuai dengan pendapat Toelihere [14] yang menyatakan bahwa motilitas sperma lebih banyak dipengaruhi oleh proses metabolisme didalam ekor sperma, yang berasal dari pemecahan fruktosa sebagai sumber energi.

\section{Kesimpulan}

Fraksi pertama nilai motilitas terbesar adalah pada nilai $80,50 \%$ dan motilitas terendah pada nilai 5,30\%. Sedangkan motilitas spermatozoa semen kambing PE fraksi kedua nilai motilitas terbesar pada nilai $81,30 \%$ dan nilai terendahnya pada 5,30\%. Kambing yang diukur merupakan satu rumpun yaitu kambing peranakan Etawa (PE), sehingga kualitas genetik yang mempengaruhi nilai motilitas tidak berbeda nyata atau tidak ada pengaruh. Berdasarkan hasil penelitian yang telah dilakukan tentang pengaruh fraksi ejakulasi dengan motilitas spermatozoa kambing peranakan Etawa (PE) dapat disimpulkan bahwa tidak ada pengaruh antara fraksi ejakulasi terhadap motilitas spermatozoa kambing peranakan Etawa (PE).

\section{Ucapan Terima Kasih}

Balai Besar Inseminasi Buatan Singosari Malang.

\section{Daftar Pustaka}

[1] Vazquez JM, Martinez EA, Parrilla I, Roca J, Gil MA, Vazquez JL. 2003. Birth of Piglets After Deep Intrauterine Insemination With Flow Cytometrically Sorted Boar Spermatozoa. Theriogenology. 59:1605-1614. 
[2] Heriyanta, E., Nur I, Dan Isnaini N. 2013. Pengaruh Umur Kambing Peranakan Etawah (Pe) Terhadap Kualitas Semen Segar. J. Ternak Tropika Vol. 14, No.2: 1-5.

[3] Batubara, A., Nasution, S., Subanriyo, 2016. Kambing Peranakan Etawa (PE). Badan Penelitian dan Pengembangan Pertanian IAARD Press. Jakarta.

[4] Hafez, E.S.E. 2000. Semen Evaluation. in Reproduction in Farm Animals. 7th ed. Lea and Febiger, Philadelphia.

[5] Toelihere, M. R. 1993. Inseminasi Buatan Pada Ternak. Angkasa. Bandung.

[6] Feredis. 2010. Bioteknologi Reproduksi pada Ternak. Alfabeta . Bandung.

[7] Setiadi, B., Subandriyo, K. Dwiyanto, T. Sartika, B. Tiesnamurti, U.D. Yulistiani dan Martawidjadja, M. 2000. Karakterisasi Sumberdaya Genetik Kambing Lokal sebagai Upaya Pelestarian Secara Ex-Situ. Balai Penelitian Ternak, Ciawi, Bogor.

[8] Toelihere M. R. 1985. Inseminasi Buatan pada Ternak. Angkasa. Bandung.

[9] Kaya, A., Varsakeli, S., and Karatzas, F., 2000. Characteristics and Seasonal Variation the semen of Alphine, Saanen and Damascus goat bucks born and raised in Greece. Theriogenology. 53: $1285-1293$.

[10] Susilawati, T., Suyadi, Nuryadi, N. Isnaini dan S. Wahyuningsih. 1993. Kualitas Semen Sapi Fries Holland dan Sapi Bali pada Berbagai Umur dan Berat Badan. Laporan Penelitian. Fakultas Peternakan Universitas Brawijaya, Malang.

[11] Evans. G. and Maxwell, W.M.C. 1987. Salamon's Artificial Insemination of Sheep and Goat. Butterworth. London

[12] Zahraddeen, D., Butswat I.S.R., Kalla, D.J.U, Sir, S.M., Bukar, M.T. 2005. Effect of Frequency of Ejaculation on Semen Characteristics in Two Breeds of Turkeys (Meleagris gallopavo) Raised in a Tropical Environment. Int. J. Poult. Sci. 4(4): 217-221.

[13] Mostari, M.P., Rahman, M.G.M., Khandoker, M.A.M.Y. and Husain, S.S. 2004. Evaluation of bulls based on semen quality and herd fertility.

[14] Toelihere, M R. 1981. Fisiologi Reproduksi pada Ternak. Angkasa. Bandung. 